\title{
RESEÑA
}

\section{Palimpsestos. Crítica y análisis literario en el aula de clases Jurado Valencia Fabio. Bogotá: Ediciones S.E.M., 2004}

\begin{abstract}
¿Salvar del olvido? Quizá por definición ésta es una lectura posible de Palimpsestos. Diremos entonces en primera instancia que este libro se constituye en la oportunidad de resguardar en la memoria de lo impreso -parafraseando al mismo autor en otro de sus libros- aquello que busca ser nombrado. Un recorrido que parte del contexto educativo colombiano para situarse en la reflexión pedagógica en torno al lenguaje y la literatura y los procesos asociados a su dimensión estética y cultural, propuesta ya como eje de trabajo curricular en los actuales lineamientos curriculares del área de lengua castellana, y con la posibilidad de desarrollarse en el aula a través de una pedagogía de proyectos, esto es, de acuerdo con esta perspectiva, la construcción en colectivo de proyectos
\end{abstract} de aula que logren conciliar intereses, necesidades e inquietudes de los estudiantes con los propósitos de formación de los maestros y de la institución en general.

Invocando una concepción semiótica del lenguaje, y desde una mirada bajtiniana de la lengua en tanto enunciado viviente constitutivo de los géneros discursivos en sus expresiones concretas, el autor se sitúa en la literatura en tanto materialización estética y artística de esa lengua, interrogando por los modos desde los cuales la escuela se acerca al estudio de las obras literarias; el carácter prescriptivo y normativo que prevalece en los currículos escolares, que, en la mayoría de los casos, subsume las posibilidades interpretativas y significativas que habitan en los universos simbólicos, polifónicos y culturales de los textos literarios.
En la perspectiva de la formación de lectores críticos, se propone entonces el estudio de la literatura como una práctica significante, que en esencia recupere el diálogo con los textos a través de una actividad mediada por el docente, lo que implica no sólo el manejo de unas teorías del lenguaje y de la crítica literaria, sino la vivencia misma de quien enseña como lector crítico, apasionado y atento a posibilitar a los estudiantes ese encuentro con las culturas, las narrativas, los mundos posibles; es el maestro quien trabajando primero con los textos y luego, interpelando a sus estudiantes, reorienta esas búsquedas, las provoca, en el sentido literal de la palabra.

Aun cuando tácitamente en este recorrido hay un llamado directo al maestro, en tanto la asunción de su responsabilidad pedagógica en la escuela, en el ya lugar común de que "los estudiantes no leen", "no quieren leer" o "no saben leer", se interroga también por las políticas culturales y educativas en el país: la pobreza de los acervos bibliográficos en las bibliotecas escolares, los escasos programas de fomento a la lectura, las limitaciones económicas de los maestros para la adquisición de libros, etc., $y$, en definitiva, aunque el autor no lo explicite en el libro, por qué no decirlo: el acumulado sociocultural de las familias y de las comunidades que en nuestro contexto general es precario, debido a las condiciones de pobreza y exclusión social en las que se vive.

No obstante, en la apuesta por ese abanico de interpretaciones y posibilidades que constituye en sí misma la lectura, este libro se centra en el trabajo peda- 
gógico con los textos, recuperando experiencias de aula, esto es, experiencias de maestros que se asumen como sujetos de saber y acción pedagógica, como lectores auténticos de la realidad que ofrecen no sólo los libros, sino también las que se producen en la interacción dialógica y cultural con los estudiantes. Esta es pues, la segunda instancia de interpretación posible; de hecho, es la más explícita en el libro: el juego con los palimpsestos, los proyectos de lectura y escritura que pueden surgir a partir de un texto y que se constituyen en la posibilidad del diálogo intertextual. Conceptos como hipertexto e hipotexte que provienen de la tecnología informática, surgen para explicar estos juegos re-creativos, que van más allá del comentario convirtiéndose en otras formas de trasvestimiento textual, textos imitados e imitadores, diálogo infinito, polifonía, posibilidad de réplica en experiencias concretas por parte de los estudiantes, y por las cuales se aboga tanto en la pedagogía. Un recorrido ilimitado hacia la recuperación del sentido de la literatura en la escuela y en la vida.

Las minificciones se constituyen aqui en el pretexto para que ello tenga lugar. Por eso el llamado a Monterroso, Torri, Arreola, etc., para representar este intento por propiciar y hacer sentir la necesidad y el contacto con la literatura entre los jóvenes de bachillerato, y llegar, desde ahí, a obras que se constituyen en el canon literario, sea universal (La Odisea o Historia del Ingenioso Hidalgo Don Quijote de la Mancha) o nacional (La Vorágine, María), que en la perspectiva cronológica, taxonómica y biográfica se defiende tanto en los contenidos curriculares, y que además no se excluyen en esta propuesta, sino que se les otorga otras maneras de abordarlos, otros sentidos.

Las propuestas pedagógicas pasan, por un lado, y como ya se dijo, por la necesidad de que el lector experto, -en este caso el maestro- sustente sus propios análisis literarios, comparta sus propias escrituras, esto es, sus propias lecturas de los textos; y de otro, por la idea de lograr análisis intertextuales que prescindan de un solo modelo. Aquí, podríamos recordar el eterno dilema para los estudiantes en los últimos años escolares: hacer un análisis literario de la obra, esto es, resumir, identificar ideas principales y secundarias, caracterizar personajes, describir argumentos, etc. Análisis que degeneraron muy pronto en tareas automatizadas y simples, no sólo porque no logran dinamizar el entusiasmo por las obras mismas, sino porque también a fuerza de ser totalmente previsibles, se estandarizaron y se convirtieron en mercancía. Así, es frecuente encontrar en el mercado la venta de los abstracts o resúmenes de las obras con análisis incluido, a menor precio que el texto genuino, pero sobre todo impulsando una economía de pensamiento, toda vez que libera al otro del acto de leer, de interpretar.
No se trataría aquí de descartar este tipo de análisis prefabricados, sino de lograr en el aula confrontaciones que provoquen la lectura crítica de los mismos. Propósito urgente, máxime cuando hoy la web también posibilita con antelación todas las respuestas a las preguntas posibles; esto es, un acumulado de informaciones que son propias del medio, pero frente a las cuales corresponde a la escuela lograr el posicionamiento de los sujetos como lectores críticos.

Volvemos al autor para reafirmar entonces que cada texto reclama "procedimientos particulares"; cada análisis es una apuesta pedagógica en la que pueden surgir experiencias como las registradas en su libro: el texto que me lleva a otro texto, y de ahí a otro, extrapolando las reflexiones, trascendiendo incluso el plano literario para volver a éste develando sus sentidos, sus temas, toda vez que estos "desencadenamientos" presuponen el llamado a otros saberes y disciplinas, según lo demande el texto mismo. Tal es el caso que se describe en la lectura-escritura de Eva de Juan José Arreola, lograda por unos estudiantes de grado noveno en un Centro Educativo Distrital.

En dicho desencadenamiento, que permite pensar un texto desde otro texto, en un efecto espiral, aparece en la última escena, y en la perspectiva semiótica que viene enunciando permanentemente el autor, una semiótica en particular, la de la imagen, el cine como ese otro texto propicio para reinventar día a día las apuestas pedagógicas por el aprendizaje significativo de la literatura en el aula de clase, que no es otro que la apuesta formativa de lectores críticos.

El libro es una evidencia de actividades específicas, de experiencias reales, con textos particulares, con sujetos reconocibles y en escenarios concretos, no obstante, susceptibles de ser recreadas, reescritas, a la manera de palimpsestos. Esta es, pues, la última lectura y la tercera instancia en este tríptico de análisis, aquella que recupera del olvido algunas respuestas a la pregunta por el cómo, por el conjunto de procedimientos, tan vitales en el aula, los de la experiencia cotidiana, los del día a día: en pocas palabras, el cómo enseñar, pregunta tan válida y legítima como la del cómo se aprende, discurso este último que, sobredimensionado con buenos propósitos, ha desplazado esta pregunta inicial, la de la necesidad de pensar la enseñan$\mathrm{za}$, las estrategias metodológicas, el qué hacer-pedagógico, tan propiamente humano, tan propio del maestro, aquello que nos hace vigentes, lo que nos recupera y nos queda como saldo en el actual contexto de despedagogización de la escuela y de la educación en Colombia.

Nylza Offir García Vera Profesora Universidad Pedagógica Nacional 